\title{
O USO DA REPRESENTAÇÃO NA MATERIALIDADE DOS IMPRESSOS ESCOLARES
}

Gabriel Amaral da Silva, Adriana Stoppock Silva, Roseli Gall do Amaral Silva.

${ }^{1}$ Centro Universitário de Maringá - UniCesumar, Maringá, PR.. ${ }^{2}$ Universidade Estadual de Maringá - UEM, Programa de Pós-Graduação em Educação, Maringá, PR. ${ }^{3}$ Universidade Tecnológica Federal do Paraná - UTFPR, Apucarana-PR. Email: gabriel100j@hotmail.com

\section{RESUMO}

O presente artigo pretende fazer uma reflexão a respeito da representação que os impressos causaram em sua época de produção e usos, a partir de manuais escolares que poderiam se configurar em uma forma de manipulação de condutas. Tomando como referências os textos de Choppin (2002) e de Goffman (2002) que respectivamente tratam do uso dos livros escolares como objeto de pesquisa para os historiadores e das formas de representações que os indivíduos atuam na sociedade como forma de transmitir uma mensagem objetiva. Compreende-se que abordar a materialidade dos impressos escolares é uma importante contribuição nas pesquisas do cotidiano escolar para a História da Educação, uma vez que nesses estão preservados aspectos do passado, que devem ser observados, para os desdobramentos da cultura escolar.

Palavras-chave: Representação; Impresso; Cotidiano escolar; Cultura escolar.

\section{THE USE OF REPRESENTATION IN THE MATERIALITY OF SCHOOL PRINTS}

\begin{abstract}
The present article intends to make a reflection about the representation that the printed ones caused in its time of production and uses, from school manuals that could be configured in a form of manipulation of conduits. Taking as reference the texts of Choppin (2002) and Goffman (2002), which respectively deal with the use of schoolbooks as an object of research for historians and the forms of representations that individuals act in society as a way to convey an objective message. It is understood that approaching the materiality of school print is an important contribution in the research of school everyday for the History of Education, since in these are preserved aspects of the past that must be observed, for the unfolding of school culture.
\end{abstract}

Keywords: Representation; Printed; School daily; School culture. 


\section{INTRODUÇÃO}

Ao observarmos a sociedade, percebe-se que ela é constituída por rupturas e permanências realizadas por instituições, oficiais ou não, que em si estão em constante mudança. Esse é o processo social, é a cultura universal, em que as sociedades formadas por sujeitos sociais encontram-se em transformações, ou seja, em movimento para o próprio desenvolvimento da cultura social da humanidade em sua totalidade.

Assim nos deparamos com a instituição escolar, um cotidiano da própria sociedade. A escola sem dúvida é a própria representação da sociedade, por meio de sua cultura, política, sujeitos e simbolismo. Ela é a referência de um cotidiano que permanece em transformação a partir de cada contexto que com o tempo, também em transformação, produzem a humanidade.

Mesmo que por um tempo, em meados e fim do século XX, e para um grupo específico, a escola tenha sido considerada como uma simples reprodutora do seu contexto, ela é na verdade uma produtora de conteúdos científicos, culturais e sociais, pois em seu ambiente ela se torna um espaço de interação que cria relações, matéria e cultura. Nesse sentido, para reconstituir a escola do passado é de suma importância investigar os vestígios de sua própria materialidade, para então traduzir o espaço cultural da escola, o que compõe a interpretação da prática escolar e suas representações por meio dos seus usos. A rotina do cotidiano é que está a ser investigada, porque é nela que se pode encontrar o sentido da própria instituição, em sua prática, em seus usos, em suas relações e produções. "Somos esse acúmulo de ações e acontecimentos culturais cotidianos, insignificantes, mas formadores necessários" (ALVES, 2003, p. 62).

Como ressalta Felgueiras (2005, p. 96) alguns tratam da escola "como se a escola não fosse uma realidade viva, que partilha com todas as outras instituições as condições sociais que as limitam ou expandem". De modo a desconsiderar a escola como uma instituição que cria e que nela estão os vestígios de tempo, espaço, cultura e uma gama de historicidade que pode ser considerada como objeto e fonte para análise do cotidiano, que passa por despercebido, mas que carrega realidade e representações significantes capazes de endossar nossas pesquisas, que por hora fundamentam-se na macro história, enquanto a micro, ou ainda a tensão entre a macro e a micro história fornecem aspectos e dimensões necessárias para a compreensão dos movimentos que a escola, e a própria sociedade produzem ao longo dos tempos.

\section{METODOLOGIA}

Utilizou-se de um levantamento bibliográfico para a construção da pesquisa. De modo a buscar em Goffman, em "A representação do eu na vida cotidiana" (2002), os desdobramentos que a pesquisa com o cotidiano auxiliam na interpretação das transformações ocorridas na esfera da história da educação contemporânea. A noção de "definição da situação", pensamento central goffmaniano que tem como expressão o processo a partir do qual se atribui um sentido ao contexto vivido, de como é compreendido o modo como as pessoas orientam suas ações na vida cotidiana.

E nesse sentido, pautando-se pela perspectiva que Choppin apresenta em "O historiador e o livro escolar" (2002), para a compreensão desse meio impresso como um veículo de informação e formação. Dialogando ainda com pesquisas recentes, como de Rodrigues e Biccas (2015), Alves (2003), que utilizaram-se dos impressos para a compreensão da cultura e, da materialidade escolar como vestígios da prática pedagógica na manifestação da historiografia da educação presente no cotidiano das instituições.

Como afirma Lima e Mioto (2007) a pesquisa bibliográfica possibilita um amplo alcance de informações, auxiliando também na construção, ou na melhor definição do quadro conceitual que envolve o objeto de estudo proposto. 


\section{RESULTADOS}

O estudo do cotidiano apresenta uma relevância histórica do que tem aparência irrelevante, mas que carregam aspectos que contextualizam o movimento de rupturas e permanência que a história discute e abrange. Em toda permanência há certa ruptura. A História Cultural busca focar essas mudanças pela vida individual e cotidiana dos homens, observando que essas modificações ocorrem no espaço de tensão, onde dá início as rupturas. Recolocando o homem no centro das discussões, uma vez que ele é o sujeito que exerce poder, conforme os contextos em que ocupa, assim o próprio sujeito se responsabiliza pelas relações sociais.

Erving Goffman (2002) ao abordar o conceito de representação na vida cotidiana elucida argumentos e definições que norteiam o modo como interpretar os acontecimentos da vida social e o papel do indivíduo para com a sociedade e seu contexto histórico, propondo a teoria da Dramaturgia Social. Transitando pela antropologia simbólica, traz elementos da vida social como: ator personificado, personagens, plateia e cenário. A fim de interpretar as manifestações que contribuem para o movimento do cotidiano e as representações em torno das instituições.

Ao considerar a materialidade como um elemento possível de fonte e objeto de pesquisa, Alain Choppin (2002) ao tratar do livro escolar e, do trabalho que historiadores têm começado a realizar em torno dele no final do século $X X$, apresenta os manuais escolares como parte da cultura escolar, ou seja, da cultura de uma instituição, que reflete de forma complexa e instrumental o cotidiano da sociedade escolar, instrumento esse que já foi irrelevante como objeto ou fonte, mas que tem muito de representatividade de uma cultura que pretende ser compreendida.

Ao tomar esses dois autores como referência observa-se a fundamentação da análise, para o século XXI, dos registros que foram deixados na materialidade da cultura escolar como uma forma de representação do movimento que a nossa cultura tem se apropriado entre as rupturas e permanências.

\footnotetext{
Recriar o passado de forma a manter o rigor necessário à operação historiográfica, sem se deixar seduzir pela possibilidade de realizar uma assepsia ao que um dia exalou o odor da putrefação, é desafio que ensina o pesquisador a mergulhar na aparente inocência das fontes, para encontrar a desordem, os limites de uma oscilação, o instante de funcionamento irregular, a delimitar os domínios possíveis da pesquisa histórica (RODRIGUES; BICCAS, 2015, p.152).
}

Há um tempo e um lugar de interação segundo Goffman (2002), onde são realizadas atividades com a capacidade de expressar-se de modo a transmitir e emitir algo, por meio de uma relação em que conta ainda com ação de receptividade. Esse tempo e lugar de interação estão vinculados à intencionalidade do indivíduo que se constitui como um ator social que por meio de sua comunicação e ação, regula a conduta do outro, com a finalidade de ser identificado da maneira como deseja, interessa-lhe transmitir uma determinada impressão, ou seja, “[...] o indivíduo evidentemente transmite informação falsa intencionalmente [...]" (GOFFMAN, 2002, p.12).

\section{DISCUSSÃO}

Ao fazer esse paralelo com os objetos de pesquisa, vale a reflexão dos sentidos exposto por Goffman (2002), uma vez que considerar a materialidade do objeto sendo esse um livro, impressos, ou algo em que a transmissão seja por escrito, faz-se necessário notar que por trás há um indivíduo ou um grupo que intelectualmente expõe suas ideias, para isso deve-se levar em conta que há a intencionalidade em regular conduta, tal como na relação de interação entre pessoas.

E assim, de certa forma também é com os objetos e fontes de pesquisas, de modo que, cabe ao pesquisador, investigar profundamente e analisar os elementos em sua pesquisa para 
compreender qual é a representação do seu objeto para o contexto em que foi produzido e consumido.

Choppin (2002), ao longo de seu artigo propõe que ao trabalhar com manuais escolares sejam observados e identificados elementos tais como: ideologia, contexto social, aspecto de produção e circulação do material, métodos de ensino, educação e etiqueta ou ainda normas de civilidade, estratégias e a própria materialidade do objeto. Para que assim possa abranger o mais completo possível a dimensão dos manuais para sua configuração e apropriação.

Além de sua característica redundante, muitas dessas produções não escapam à mediocridade: sofrem de graves insuficiências metodológicas, apresentam análises superficiais e chegam, muitas vezes, a conclusões discutíveis, até mesmo infundadas (CHOPPIN, 2002, p.11).

O estudo do cotidiano possibilita verificar que a ação dos indivíduos e da sociedade não está atrelada para a estrutura econômica apenas, mas para a própria ação do indivíduo diante de um grupo, ou plateia de maneira que o colapso do sistema social de interação pode ocorrer quando a representação é desacreditada. Cabe, desse modo, ao pesquisador identificar, com metodologia, as razões desses colapsos, e não apenas suas causas e consequências, mas o cotidiano, a tensão, contribuindo para o campo da historiografia na construção das produções, apropriações, usos e consumos dos objetos, como, por exemplo, manuais e impressos de determinadas épocas no ambiente da cultura escolar.

Uma vez que o ambiente social é o palco da transmissão, as ações institucionais, individual ou coletiva, se tornam representação capaz de mobilizar comportamentos, assim como os impressos em forma de manuais, livros ou jornais da comunidade escolar, expressam um modo de agir social, que se configuram como depositários de conteúdo educativo.

Quando em contato com um impresso esse se torna o palco de transmissão, então se faz necessário identificar primeiramente as condições desse "palco de transmissão", e oportunamente as manifestações que foram selecionadas e registradas como forma de discurso, e enfim aprofundar o olhar para a investigação dos papéis desenvolvidos do cotidiano vivido de outrora. É uma árdua tarefa que busca compreender não só o que foi mantido, mas principalmente analisar os porquês e as escolhas feitas para a conservação de uma ideologia aplicada em um tempo e lugar de interação.

A despeito de nossa boa vontade em apreciar as exigências expressivas desses vários tipos de situações, tendemos a vê-las como casos especiais; inclinamo-nos a nos manter cegos para o fato de que representações diárias seculares, em nossa própria sociedade angloamericana, devem passar muitas vezes por uma rigorosa prova de idoneidade, conveniência, propriedade e decoro. Talvez esta cegueira se deva, em parte, ao fato de que, como atores, como frequentemente mais conscientes dos padrões que deveríamos ter aplicado à nossa atividade, mas não o fizemos, do que dos padrões que irrefletidamente utilizamos. De qualquer modo, como estudiosos, devemos estar preparados para examinar a dissonância criada por uma palavra incorretamente escrita ou por uma combinação que aparece sob a saia [...] (GOFFMAN, 2002, p.57).

Rodrigues e Biccas (2015) conceituam que a função objetiva do impresso é a operar materialmente com a ideia de que a problematização deve ser sua finalidade. Pois todo impresso considerado pedagógico propõe, com forte intenção, maneiras de ensinar e está destinado à um público específico, assim considerando o conceito de representação de Goffman (2002), nele se encontra sujeitos sociais que materialmente representam e expressam, emitem sua forma de conduta desejada.

Os impressos são construtores de realidade representativa, onde está exposta uma história escrita, que deve ser comparada a história vivida, por meio dos seus usos e cultura escolar. Nessa história escrita há o conceito de que somos formados por aquilo que lemos, logo, analisar os conteúdos de livros e o diversos impressos escolares é indispensável, pois esse está associado aos 
usos reais ou pretendentes, as representatividades auxiliam na multiplicidade da produção de livros. De maneira que

Os manuais representam para os historiadores uma fonte privilegiada, seja qual for o interesse por questões relativas à educação, à cultura ou às mentalidades, à linguagem às ciências... ou ainda à economia do livro, às técnicas de impressão ou à semiologia da imagem. O manual é, realmente, um objeto complexo dotado de múltiplas funções, a maioria, aliás, totalmente desapercebidas aos olhos dos contemporâneos (CHOPPIN, 2002, p.13).

Constituindo-se o manual um objeto material, histórico, rico e complexo da cultura e do cotidiano escolar, vindo a ser um meio de revisitar o passado e identificar as formas de representações de conduta para as gerações, servindo em alguns casos como um doutrinamento, e como forma de observação e conhecimento de como ocorriam as representações dos comportamentos sociais, ao longo da história da educação. Nisso encontra-se os desdobramentos da própria história na busca por investigar as rupturas e permanência, podemos interagir com o conceito de que o manual escolar é na verdade, uma continuidade que se expressa por meio de suas reedições, alterando formas de se expressar e que permanece até hoje, em materialidade diferente ou diversa.

Tanto as representações como os manuais são expressões de um ser, ou seja, são expressões do mundo social de interações, em que o que está sendo representado é a realidade, o cotidiano, a rotina, a cultura, a história real da vida dos homens em sociedade em aspectos específicos, como no caso da escola. A historiografia não pode negar isso, mas deve valer-se de que independe do que se lê são as aparências que se fizeram registar, as aparências que se perpetuam nos impressos cheios de vestígios da cultura escolar. E nisso é que se materializa o campo da pesquisa.

Uma condição, uma posição ou um lugar social não são coisas materiais que são possuídas e, em seguida, exibidas; são um modelo de conduta apropriada, coerente, adequada e bem articulada. Representando com facilidade ou falta de jeito, com consciência ou não, com malícia ou boa-fé, nem por isso deixa de ser algo que deva ser encenado e retratado e que precise ser realizado (GOFFMAN, 2002, p.74).

Diante disso, podemos considerar que o valor de contribuição a pesquisa com os manuais escolares não está diretamente relacionado ao que ele mostra, aparenta ou como foram feitos, mas o que pretendeu que fosse exposto. Não são apenas os conteúdos que nele estão, mas a proposta de tais, as razões, o porquê das aparências. Necessita ser dissecado e compreender a intencionalidade na maneira como foi apresentado simbolicamente, e em um segundo aspecto a apropriação deste no ambiente e para a cultura escolar.

\section{CONCLUSÃO}

Ao abordar o impresso como fonte de pesquisa, considerando a representação como meio de compreender e analisar a história da cultura escolar, as abordagens são múltiplas e devem ter como ponto de partida o contexto das relações em que foram concebidos os impressos.

Ao refletir sobre as representações do homem em seu espaço de interação, e, propositalmente no plural, devido ao fato de que cada um representa o grupo a que se adequa, esse conceito precisa ser explicitado, já que cada indivíduo emite uma mensagem e uma postura que primeiramente passa pela identificação e posteriormente pelo tratamento metodológico. Ao transportar esse conceito para o campo dos manuais e impressos, vale a mesma observação.

O cotidiano, e em específico, o escolar não se limita apenas a rotina pragmática da estrutura escolar, mas vai além de suas burocracias, tendências, metodologias e organização social. Esse cotidiano são as ações e as manifestações de um espaço de interação que produz suas próprias representações e fontes de usos e relações. Cabe, entretanto ao pesquisador desvendar, 
quase como um arqueólogo, esse cotidiano e suas produções, que embora nem sempre sejam explícitas, estão lá, para serem significadas.

Compreendendo que o cotidiano, uma vez significado, está contemplado de materialidade e símbolos que demonstram as manifestações dos diversos grupos envolvidos na escola, seus costumes e a maneira como deram continuidade a cultura da escola.

A sociedade moderna tem a escola como a instituição que forma os sujeitos, sendo assim, ao olhar para a instituição escolar da modernidade encontra-se os vestígios das ideologias em que foram, ou pretendiam ser formados os sujeitos. Os impressos e manuais estão carregados de discursos de conduta e de formação à uma geração, que em suas relações se identificam e diferenciam pela representação.

Ao utilizar como fonte um manual escolar almeja-se identificar o cotidiano de uma determinada cultura escolar, pelo viés da representação, como forma de problematizar seu discurso e enriquecer a historiografia da educação, considerando que o cotidiano e os impressos não são acabados em suas ideias, pois cada indivíduo se apropria de uma forma do que está representado.

\section{REFERÊNCIAS}

ALVES, Nilda. Cultura e cotidiano escolar. Revista Brasileira de Educação, Rio de Janeiro, n. 23, p.62-74, Ag. 2003. Disponível em http://www.ia.ufrrj.br/ppgea/conteudo/conteudo-20092/Educacao-MII/2SF/Cultura_e_Cotiadiano.pdf. Acesso: em 05 de agosto de 2017.

CHOPIN, Alain. O historiador e o livro didático. In: História da Educação. ASPHE/FaE/UFPel, Pelotas(11):5-24, Abr. 2002.

GOFFMAN, Erving. A representação do eu na vida cotidiana. Petropólis: vozes, 2002.

FELGUEIRAS, Margarida Louro. Materialidade da cultura escolar. A importância da museologia na conservação/comunicação da herança educativa. In: Pro-Posições. v. 16, n. I (46) - jan./abr. 2005.

LIMA, Telma Cristiane Sasso de; MIOTO, Regina Célia Tamaso. Procedimentos metodológicos na construção do conhecimento científico: a pesquisa bibliográfica. Revista Katalysis, v. 10, p. 35-45, 2007.

RODRIGUES, Elaine; BICCAS, Maurilane de Souza. Imprensa pedagógica e o fazer historiográfico: o caso da Revista do Ensino (1929 - 1930). Acta Scientiarum. Education, Maringá, v. 37, n. 2, p. 151163, Apr.-June, 2015. 